\title{
DETERMINING ROCK PORE SPACE USING IMAGE PROCESSING METHODS
}

\author{
Lukasz MAZURKIEWICZ \& Mariusz MLYNARCZUK \\ AGH University of Science and Technology, Faculty of Geology, \\ Geophysics and Environmental Protection, Department of Geoinformatics \\ and Applied Computer Science; \\ al. Mickiewicza 30,30-059 Krakow, Poland; \\ e-mail: lmazurkiewicz87@gmail.com,mlynar@agh.edu.pl
}

\begin{abstract}
This paper presents the possibilities of using image processing for determining effective porosity in carbonate and terrigenous rocks. For the purpose of the research, an algorithm was created, which automatically determines the percentage of pore space, based on the analysis of video sequences registered with the use of a microscope. Up to this point stereological research used for describing rock porosity was conducted manually, which is both troublesome and time consuming. The proposed algorithm uses a series of transformation operations such as: non-context operations, contextual operations and morphological transformations. The presented algorithm was tested on video sequences of thin sections of carbonates from Buszewo and Kościan, and sandstones from Dobrzyca and Solec. The obtained results show, that the method of automatic video sequence analysis used for detection and measurement of porosity leads to satisfying results.
\end{abstract}

Key words: porosity, image analysis, mathematical morphology

\section{INTRODUCTION}

Image analysis has been used for many years in order to extract relevant information from geological images. In this paper, this method is used to describe pore space in reservoir rocks, based on the analysis of video sequences. Porosity, which is one of the main parameters of reservoir rocks is a result of complicated, long-term sedimentation processes and diagenesis. Pore space and, in consequence, reservoir parameters of the rock can be characterized by a specific distribution of size and shape of the pore structure. It is usually determined through the use of physical methods (Leśniak \& Such 1999). For a more accurate description of pore space parameters, there is a need to conduct stereological measurements. In these measurements the quantitative information about a three-dimensional structure is obtained from measurements made on two-dimensional planar sections of the structure (Ratajczak et al. 1998). These methods tend to be time-consuming, therefore it is desirable to create an algorithm which would automatically calculate the pore space 
percentage of a rock. The algorithm proposed in this paper uses the methods of image processing. The algorithm calculates the effective porosity based on video recordings created using a CCD camera, which registers the image of a thin-section placed under a microscope. The method enables measuring the rock porosity during its inspection under a microscope without the need to register images. It is a step forward compared to the previous research described, for example, by Ratajczak et al. (2004) and Młynarczuk et al. (2005), which demanded many microscopic pictures. It should be noted that this paper uses some terminology related to image processing. The relevant definitions can be found in Sierra (1982), Wojnar \& Majorek (1994), Tadeusiewicz \& Korohoda (1997).

\section{RESEARCH MATERIAL}

For research purposes lithologically diverse rocks were selected. These are terrigenous rocks represented by silica-cemented quartz sandstone of the Lower Carbonaceous (Visean), drilled in Dobrzyca along with a quartz sandstone with iron oxide cement from the Lower Permian drilled in the region of Solec. In addition, two Lower Permian (Zechstein) carbonate rocks were selected - a sparry, epigenetic dolomite from a well sunk in the Main Dolomite at Buszewo, and a fine-grained sparry dolomite from Kościan.

The analyzed samples were impregnated in vacuum with blue-coloured glue. This resulted in the pore space contrasting with the rest of the rock and clearly distinguishable under the petrographic microscope. For the purpose of image registration an Zeiss polarisation microscope and a CCD camera (dedicated for microscopic image registration) were used. A video sequence of approximately 1 minute in length was registered for every thin section. The sequences were recorded with a frequency of 30 frames per second and a resolution of $1024 \times 1280$ pixels (which corresponds to a size of roughly $1300 \times 1700 \mu \mathrm{m}$ ). The example video frames images are presented in Figures 1 and 2.

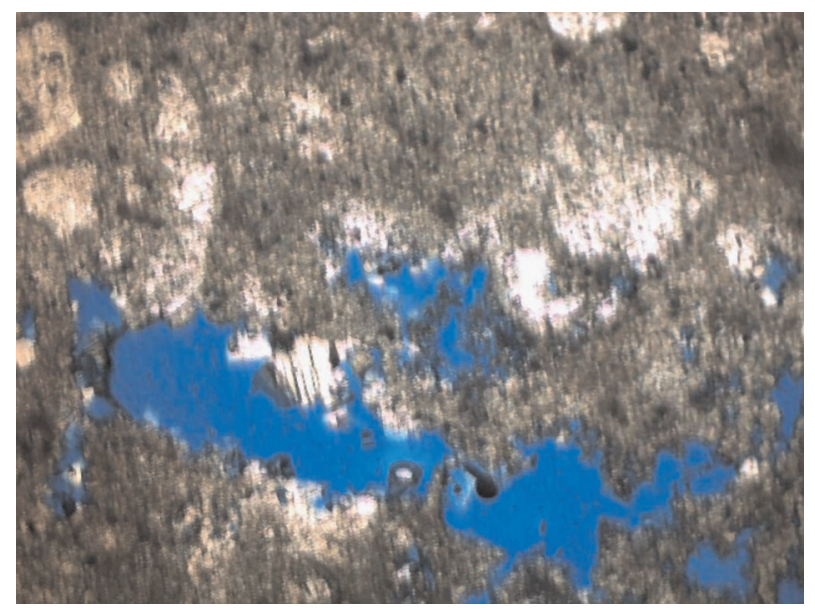

Fig. 1. The frame image of the dolomite from Buszewo, 100× 


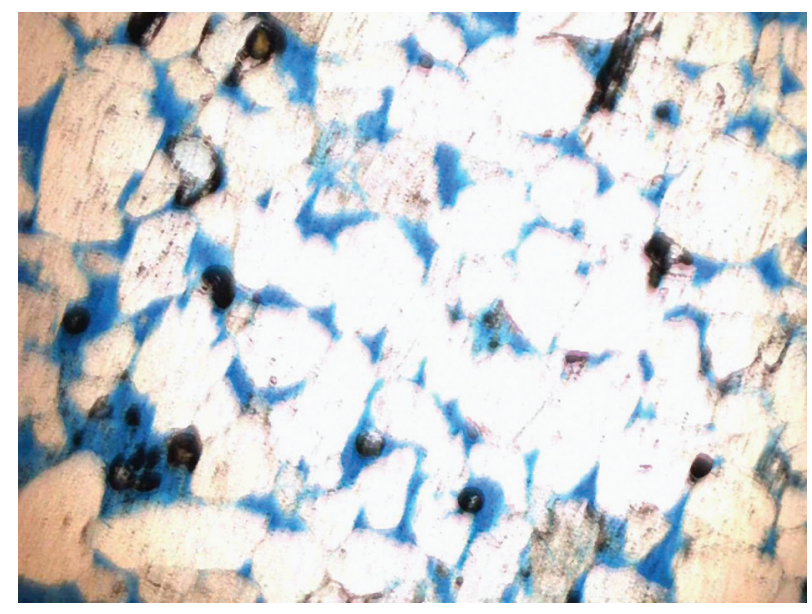

Fig. 2. The frame image of the sandstone from Dobrzyca, 100×

\begin{abstract}
ALGORITHM
The algorithm was based on image processing and image analysis operations. These operations were implemented in Mathworks Matlab software.

The algorithm used for calculating the pore space consists of several steps. The first stage involves loading the video sequence, dividing it into individual frames along with cutting out the edges of the images to a total resolution of $960 \times 1280$. This step is necessary because of the fact that the recording software creates empty 32 pixel-wide areas in the top and bottom of the frames. During the next step, the main loop of the algorithm is executed, which reads selected frames determined by a given interval. This is done due to the fact that not every frame of the sequence needs to be taken into account during the analysis. The interval was set to 30 frames, although it can be changed to any natural number value. Next, every frame is processed with a morphological alternating filter (opening of size 1 following by closing of size 1). After filtering, the frames are binarized with set cut-off values in the RGB colour model. The resulting images show preliminarily identified pore space areas. For the purpose of eliminating the noise resulting from binarization, once again the alternating filter was used - this time with the size value set to 2 . The results of these operations for the images shown in Figures 1 and 2 are presented in Figures 3 and 4. After filtering, the percentage of the pore space can be calculated for every frame, which is equivalent to the percentage of white pixels in the image. Determining the pore space for the entire sequence is a more complicated task. If every frame of the sequence is shifted by an equal amount of pixels, it's possible to sum up the porosity values of all frames and divide by the number of the processed frames. In reality this requirement, which is equivalent to always evenly moving the sample in only one direction, highly limits the observer. In most cases, the sample is moved by uneven intervals. Additionally, this research assumes that the sample movement may stop for a given amount of time, the direction of the movement may
\end{abstract}


be changed or the movement may even proceed in the direction of the previously observed areas. All this makes the frames of the sequence unevenly spaced. In this case, the first step is calculating the displacement vector between neighbouring, analysed frames. For this purpose, the algorithm presented by Rudnicki (2010) is used. Next, the porosity of the new frame is determined, but only for the area that was not visible in the previous frames.

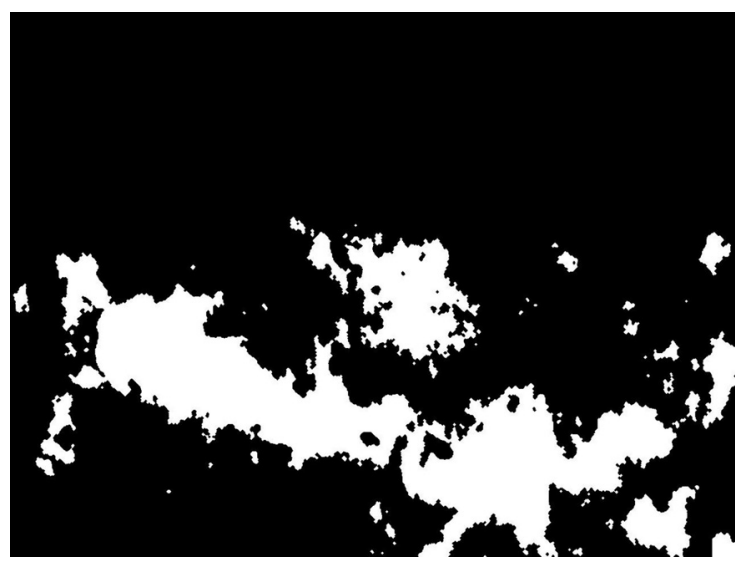

Fig. 3. The result of binarization of the frame from Figure 1

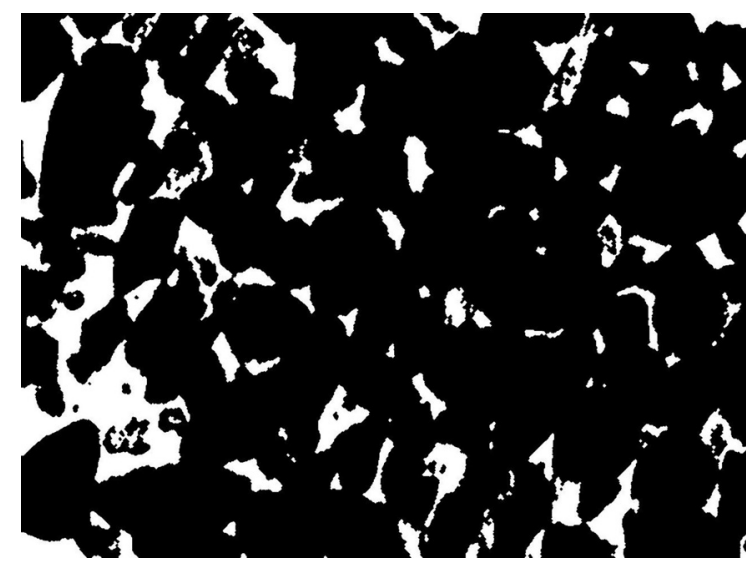

Fig. 4. The result of binarization of the frame from Figure 2

That area is identified using the following method:

- determining the intersection of the currently analyzed frame and all of the previously processed ones,

- assigning zero values to pixels on the currently analyzed frame in the area determined in the previous step. 
The porosity is determined by using image volume method to summing up porosity pixels of all analyzed frames ("total porosity" in the flow chart) and by dividing that value by the sum of the areas observed on these frames ("total capacity" in the flow chart). Then the obtained value is multiplied by $100 \%$. These calculations have been conducted without taking into account those areas, which are located in the previous analysed frames. The algorithm's flow chart is presented in Figure 5.

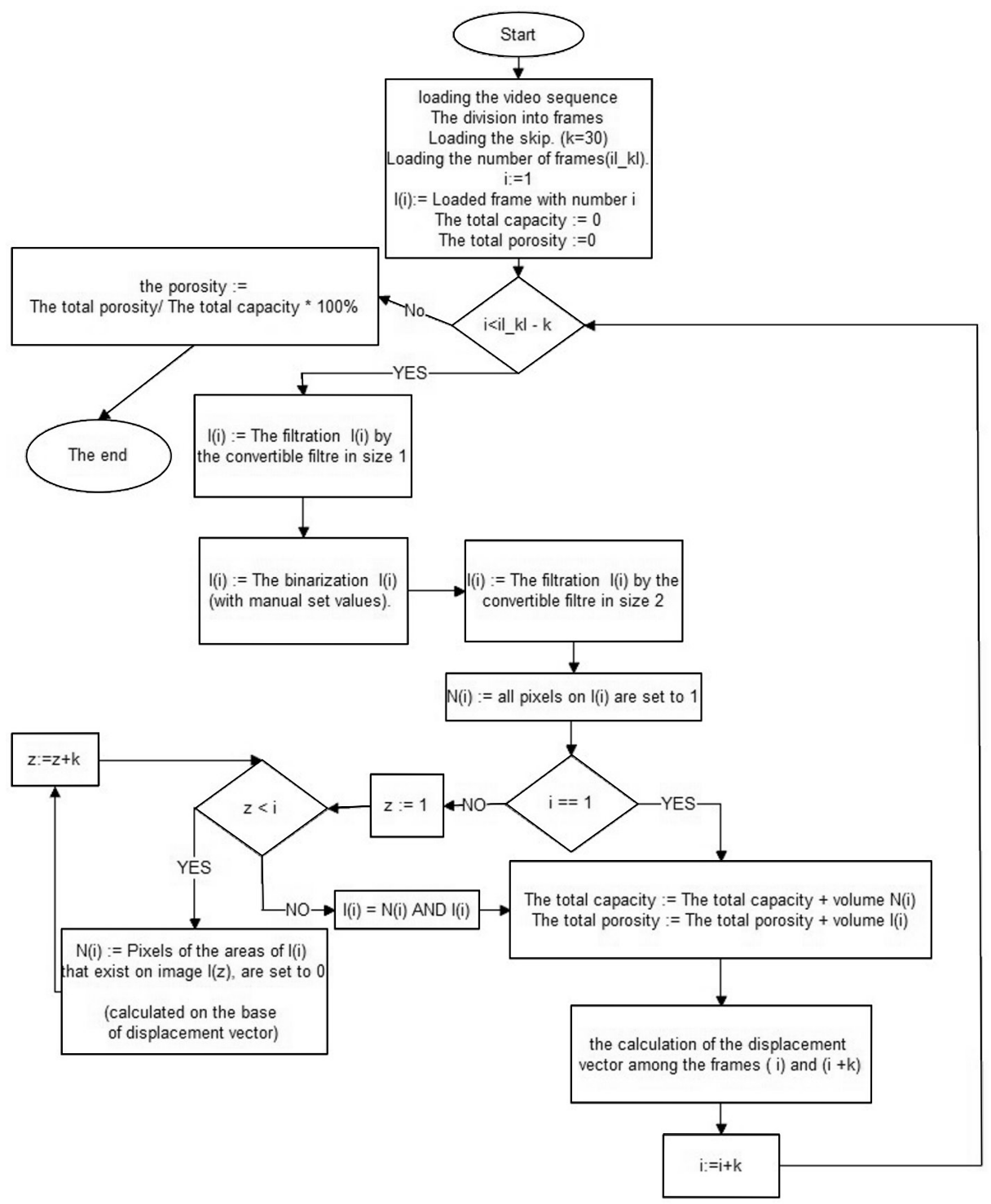

Fig. 5. The algorithm's flowchart 


\section{RESULTS}

As already mentioned, for the initial analysis two carbonate rock samples were selected. For the Buszewo dolomite one thin section was analyzed and five video sequences were recorded for it. Table 1 presents the results and length of each of these sequences. The determined average porosity value is $10.3 \%$.

The second analyzed rock was the Kościan dolomite. Table 2 presents the results. The average porosity value is $20.1 \%$.

Table 1

Results of analysis of video sequences for Buszewo carbonate

\begin{tabular}{|c|c|c|c|c|c|}
\hline \multirow{2}{*}{ Parameter } & \multicolumn{5}{|c|}{ Sample number } \\
\cline { 2 - 6 } & 1 & 2 & 3 & 4 & 51 \\
\hline $\begin{array}{c}\text { Time of the video } \\
\text { sequence [s] }\end{array}$ & 57 & 49 & 58 & 57 \\
\hline $\begin{array}{c}\text { Porosity calculated } \\
\text { on video sequence [\%] }\end{array}$ & 9.9 & 8.8 & 10.6 & 10.5 & 11.5 \\
\hline Average [\%] & \multicolumn{5}{|c|}{0.9} \\
\hline Standard deviation & & 10.3 & \\
\hline
\end{tabular}

Table 2

Results of analysis of video sequences for Kościan carbonate

\begin{tabular}{|c|c|c|c|c|c|}
\hline \multirow{2}{*}{ Parameter } & \multicolumn{5}{|c|}{ Sample number } \\
\cline { 2 - 6 } & 1 & 2 & 3 & 4 & 5 \\
\hline $\begin{array}{c}\text { Time of the video } \\
\text { sequence [s] }\end{array}$ & 59 & 44 & 47 & 45 & 24 \\
\hline $\begin{array}{c}\text { Porosity calculated } \\
\text { on video sequence [\%] }\end{array}$ & 17.4 & 21.4 & 20.7 & 21.0 & 19.8 \\
\hline Average [\%] & \multicolumn{5}{|c|}{20.1} \\
\hline Standard deviation & 1.4 \\
\hline
\end{tabular}

After analyzing the carbonate rocks, clastic rocks were investigated represented by the Dobrzyca and Solec sandstones. Table 3 presents the results for the Dobrzyca sandstone and Table 4 presents the analysis results for the Solec sandstone. 
Table 3

Results of analysis of video sequences for Dobrzyca sandstone

\begin{tabular}{|c|c|c|c|c|c|}
\hline \multirow{2}{*}{ Parameter } & \multicolumn{5}{|c|}{ Sample number } \\
\cline { 2 - 6 } & 1 & 2 & 3 & 4 & 5 \\
\hline $\begin{array}{c}\text { Time of the video } \\
\text { sequence [s] }\end{array}$ & 59 & 59 & 58 & 60 \\
\hline $\begin{array}{c}\text { Porosity calculated } \\
\text { on video sequence [\%] }\end{array}$ & 23.0 & 20.3 & 18.3 & 19.5 & 23.1 \\
\hline Average [\%] & \multicolumn{5}{|c|}{20.8} \\
\hline Standard deviation & \multicolumn{5}{|c|}{1.9} \\
\hline
\end{tabular}

Table 4

Results of analysis of video sequences for Solec sandstone

\begin{tabular}{|c|c|c|c|c|c|}
\hline \multirow{2}{*}{ Parameter } & \multicolumn{5}{|c|}{ Sample number } \\
\cline { 2 - 6 } & 1 & 2 & 3 & 4 & 53 \\
\hline $\begin{array}{c}\text { Time of the video } \\
\text { sequence [s] }\end{array}$ & 57 & 34 & 40 & 26 & 25.9 \\
\hline $\begin{array}{c}\text { Porosity calculated } \\
\text { on video sequence [\%] }\end{array}$ & 23.6 & 23.7 & 25.4 & 24.9 \\
\hline Average [\%] & \multicolumn{5}{|c|}{1.1} \\
\hline Standard deviation & \multicolumn{5}{|c|}{} \\
\hline
\end{tabular}

The results, which are presented in the tables are similar to those presented in previous work focused on analyzing these rocks by Ratajczak et al. (2004) and Młynarczuk et al. (2005). The main advantage of the proposed method is that it requires no registration of images. All calculations might be done on registered video or even on-line, directly into the video stream, which is transmitted from the CCD camera to the computer. Furthermore, the proposed algorithm does not require any special way of manipulating the analyzed thin section when the measurements are taken. Permitted is both fast and slow movement of the section, as well as stopping it for any length of time. Multiple view of the same part of the section is allowed as this does not affect the final result. The result depends only on the investigated area of the specimen. The greater the part of the section has been viewed the closer to the actual porosity of the specimen the result appears. These advantages of the proposed algorithm make it more interesting than the standard methods used in image analysis, based on measurements of several, or several dozen, images evenly spaced across the specimen. 
It is important to note, that the research presented in this paper doesn't aim at a statistically accurate description of the analyzed rock's porosity but is focused exclusively on proposing image processing methods for detecting rock porosity and describing it quantitatively.

\section{DISCUSSION}

The article presents a new method of determining rock porosity with the use of video sequence analysis. Correct determination of porosity is of key importance in the oil and gas industry. It's usually conducted with the use of physical methods (Leśniak \& Such 1999). For a more detailed parameter description, stereological measurements are necessary. Traditional methods, in comparison to image processing methods are time-consuming. Scientists for years have been trying to replace traditional quantitative methods with image processing (Ghiasi-Freez et al. 2012). They proved that the results obtained with the use of image processing are similar to those obtained by traditional stereological methods. To assess the correctness of the results in this paper, they need to be compared with the results presented in other publications, which present the results of investigations of the same material with different methods. Such type of research is presented in the work of Młynarczuk et al. (2005). Table 5 presents the results obtained on samples investigated by both photograph analysis and video sequence analysis.

\section{Table 5}

Porosity values determined by two different methods

\begin{tabular}{|c|c|c|c|c|}
\hline \multirow{2}{*}{ Parameter } & \multicolumn{4}{|c|}{ Rock name } \\
\cline { 2 - 5 } & Buszewo & Kościan & Dobrzyca & Solec \\
\hline $\begin{array}{c}\text { Porosity determined by photograph } \\
\text { analysis [\%] }\end{array}$ & 9.2 & 18.2 & 19.7 & 24.2 \\
\hline $\begin{array}{c}\text { Porosity determined by video sequence } \\
\text { analysis [\%] }\end{array}$ & 10.3 & 20.1 & 20.8 & 24.9 \\
\hline \begin{tabular}{c} 
Percentage difference [\%] \\
\hline
\end{tabular} & 10.7 & 9.5 & 5.3 & 2.8 \\
\hline
\end{tabular}

As we may observe, the results for the two methods are comparable, which implies that the results obtained by the proposed method are correct. Porosity research is not necessarily applicable only to geology, as it can be used in other fields of science. An interesting example, especially in light of the recently formed AGH Historical Research Center, is successful application of image processing methods for determining the porosity of archeological and historical building materials (Miriello \& Crisci 2006). 


\section{CONCLUSIONS}

This paper proposes an algorithm, which automatically determines rock porosity, based on video sequence analysis. The main goal of the presented research was to automate the quantitative measurements process, which in the standard, non-automatic form is time consuming and troublesome for the observer. The proposed algorithm enables measuring the porosity of an observed rock on individual video sequence frames. Because of the implementation of an algorithm, which detects and records movement parameters of the rock sample, the porosity analysis can be conducted regardless of the movement velocity and direction of the sample under a microscope. It enables porosity measurements during preliminary rock observations or during other, more advanced research. The presented algorithm measures a sample with specific parameters (thin section injected with colorized glue). However, with minor changes, the proposed method may be used for measuring another samples and objects. The results obtained on both carbonate and sandstone samples confirm the effectiveness of the proposed concept. Research in progress aims at optimizing and parallelizing the presented algorithm, which would enable real time porosity analysis. It will become then a fully functional tool, which could be used on any microscope equipped with a CCD camera.

\section{REFERENCES}

Ghiasi-Freeza J., Soleimanpourb I., Kadkhodaie-Ilkhchic A., Ziaiia M., Sedighid M. \& Hatampoure A., 2012. Semi-automated porosity identification from thin section images using image analysis and intelligent discriminant classifiers. Computers \& Geosciences, 45, 36-45.

Leśniak G. \& Such P., 1999. Analiza przestrzeni porowej skał zbiornikowych czerwonego spagowca z południowej części niecki poznańskiej przy zastosowaniu komputerowej analizy obrazu i modeli perkolalacyjnych. Przeglad Geologiczny, 47, 5, 84-85.

Miriello D. \& Crisci G.M., 2006. Image analysis and flatbed scanners. A visual procedure in order to study the macro-porosity of the archaeological and historical mortars. Journal of Cultural Heritage, 7, 3, 186-192.

Młynarczuk M., Ratajczak T. \& Szydłak T., 2005. Possible replacing traditional rock porositymeasurements by rock image analysis. Polskie Towarzystwo Mineralogiczne. Prace. Specjalne, 27, 37-49.

Ratajczak T., Magiera J., Skowroński A. \& Tumidajski T., 1998. Ilościowa analiza mikroskopowa skat. Skrypty Uczelniane AGH nr 1534, Wydawnictwa AGH, Kraków.

Rudnicki Z., 2010. Metody komputerowej analizy obrazów w badaniach tribologicznych. Wydawnictwa AGH, Kraków. 
Serra J., 1982. Image Analysis and Mathematical Morphology. Academic Press.

Tadeusiewicz R. \& Korohoda P., 1997. Komputerowa analiza i przetwarzanie obrazów. Wydawnictwo Fundacji Postępu Telekomunikacji, Kraków.

Wojnar L. \& Majorek M., 1994. Komputerowa analiza obrazu. Wyd. Fotobit Design, Kraków. 